\title{
Effects of Cell Culture Media on the Dynamic Formation of \\ Protein-Nanoparticle Complexes and Influence on the Cellular Response
}

\author{
Gabriele Maiorano, Stefania Sabella,* Barbara Sorce, Virgilio Brunetti, Maria Ada Malvindi, \\ Roberto Cingolani, and Pier Paolo Pompa* \\ Italian Institute of Technology, Center for Bio-Molecular Nanotechnology, Via Barsanti-73010 Arnesano, Lecce, Italy
}

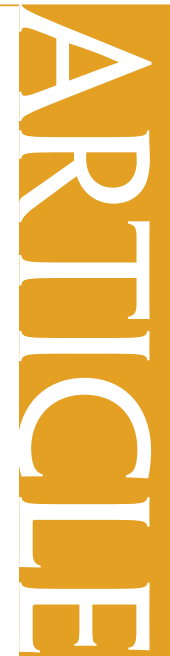

$\mathrm{E}$ ngineered nanomaterials, with typical dimensions lower than $100 \mathrm{~nm}$, are increasingly used by industries in such areas as microelectronics, catalysis, biosensors, diagnostics, and pharmaceutics. The unique physicochemical properties induced by nanoscale dimensions result in enhanced performances in terms of reactivity, conductivity, and optical sensitivity of nanomaterials compared to their bulk counterparts. ${ }^{1}$ Nevertheless, increasing evidence is pointing at the same peculiar properties as possible causes of adverse effects in living systems..$^{2-10}$ Thus, the evaluation of the risk associated with nanoparticles (NPs) on human health has to be urgently faced. ${ }^{11}$ However, NPs do not behave in solution as inert objects or soluble small molecules. Rather, they often undergo aggregation and/or agglomeration processes, leading to the formation of a new range of multisized and unknown molecular entities. ${ }^{12,13}$ The change of physicochemical properties of the NPs (including size, shape, surface area, and surface reactivity) possibly causes different biological responses and thus an inaccurate assessment of the toxicity of NPs, also due to a problematic determination of their dose. ${ }^{10,14,15}$ Beyond the intrinsic behavior of NPs, experimental parameters such as the characteristics of the surrounding environment (i.e., ionic strength of buffer media, $\mathrm{pH}$ values, presence of plasma proteins as additional nutrient sources) further contribute to increase the uncertainty about the molecular entities that cells encounter in solution. ${ }^{16,17}$ Additionally, NPs suspended in biological fluids are known to adsorb a set of different proteins (referred to as protein corona), ${ }^{18,19}$ whose composition and af-
ABSTRACT The development of appropriate in vitro protocols to assess the potential toxicity of the ever expanding range of nanoparticles represents a challenging issue, because of the rapid changes of their intrinsic physicochemical properties (size, shape, reactivity, surface area, etc.) upon dispersion in biological fluids. Dynamic formation of protein coating around nanoparticles is a key molecular event, which may strongly impact the biological response in nanotoxicological tests. In this work, by using citrate-capped gold nanoparticles (AuNPs) of different sizes as a model, we show, by several spectroscopic techniques (dynamic light scattering, UV - visible, plasmon resonance light scattering), that proteins -NP interactions are differently mediated by two widely used cellular media (i.e., Dulbecco Modified Eagle's medium (DMEM) and Roswell Park Memorial Institute medium (RPMI), supplemented with fetal bovine serum). We found that, while DMEM elicits the formation of a large timedependent protein corona, RPMI shows different dynamics with reduced protein coating. Characterization of these nanobioentities was also performed by sodium dodecyl sulfate polyacrylamide gel electrophoresis and mass spectroscopy, revealing that the average composition of protein corona does not reflect the relative abundance of serum proteins. To evaluate the biological impact of such hybrid bionanostructures, several comparative viability assays onto two cell lines (HeLa and U937) were carried out in the two media, in the presence of $15 \mathrm{~nm}$ AuNPs. We observed that proteins/NP complexes formed in RPMI are more abundantly internalized in cells as compared to DMEM, overall exerting higher cytotoxic effects. These results show that, beyond an in-depth NPs characterization before cellular experiments, a detailed understanding of the effects elicited by cell culture media on NPs is crucial for standardized nanotoxicology tests.

KEYWORDS: gold nanoparticles - nanotoxicity - protein corona • nanobiointeractions $\cdot$ in vitro studies

finity kinetics strongly depend on the surface, size, and concentration of the particles. Hence, the protein coating, surrounding and hiding the surface of NPs, plays a pivotal role in determining the effective size, surface charge, and aggregation state of the newly formed hybrid bionanomaterials, influencing biodistribution and, finally, triggering the beneficial or hazardous biological effect. ${ }^{20,21} \mathrm{~A}$ detailed characterization of the dispersion state of nanomaterials as well as knowledge of the experimental parameters controlling such changes have, therefore, significant implications for the
*Address correspondence to pierpaolo.pompa@iit.it, stefania.sabella@iit.it.

Received for review July 7, 2010 and accepted November 04, 2010.

Published online November 17, 2010. 10.1021/nn101557e

() 2010 American Chemical Society 


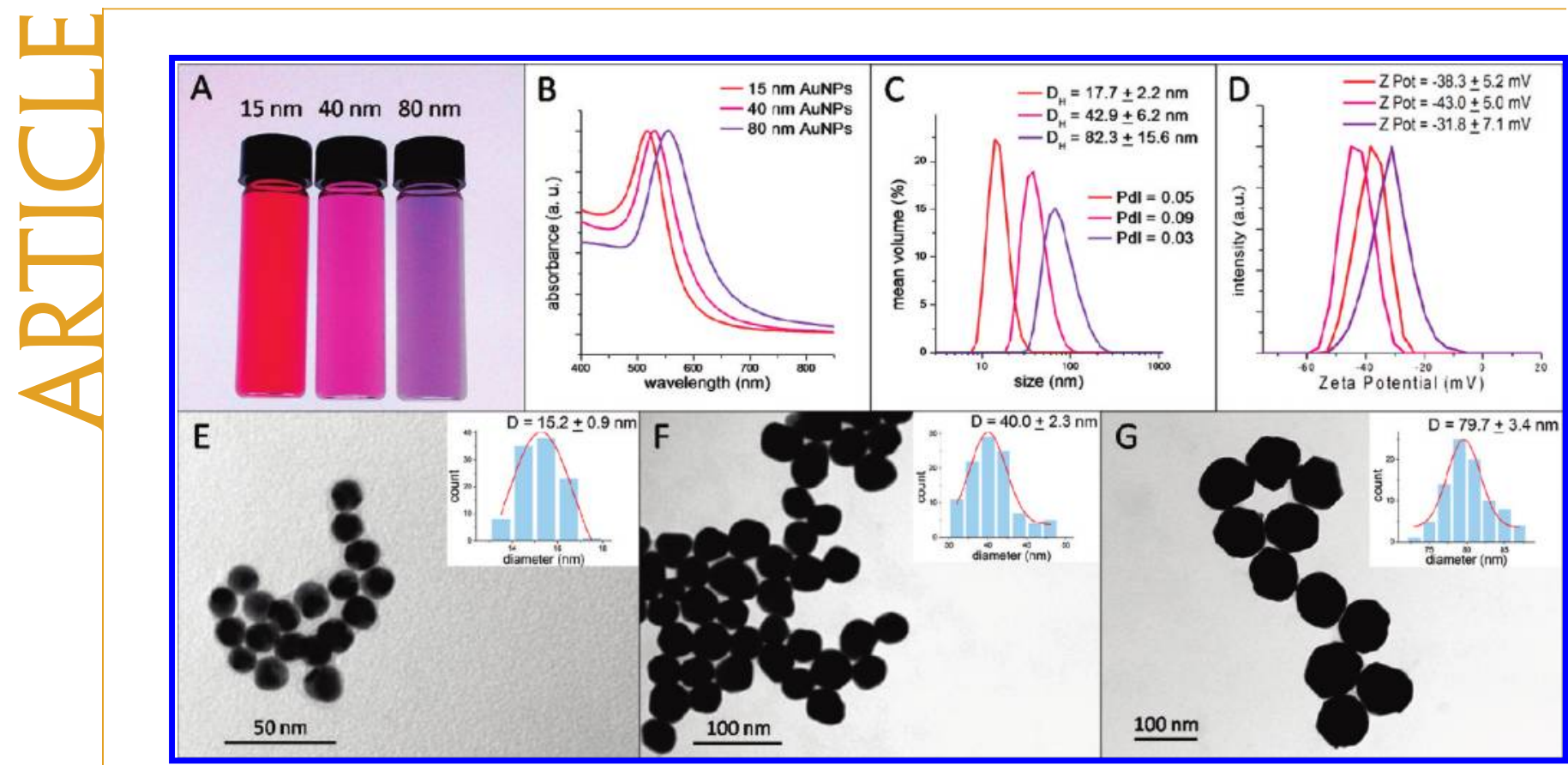

Figure 1. (A) Photograph of 15, 40, and $80 \mathrm{~nm}$ citrate-capped AuNPs suspended in aqueous solution after synthesis; (B) absorption spectra; (C) DLS, and (D) Z-potential analyses; (E-G) TEM images of 15, 40, and $80 \mathrm{~nm}$ AuNPs in deionized water. Values given are mean \pm standard deviation averaged over at least 100 nanoparticles. DLS measurements are the average of at least 10 runs each containing 15 submeasurements. Pdl = polydispersion index; Z-potential measurements are the average of at least 10 runs each containing 30 submeasurements.

development of reliable in vitro toxicity protocols and predictive models of the biological response..$^{10,14,15,22-26}$

In this work, we studied the nanobiointeractions occurring between commonly used cell culture media and differently sized AuNPs to determine how media composition influences the formation of protein/NP complexes that, in turn, may affect the cellular response. This may provide important information for protocols in in vitro studies. To this purpose, we performed an accurate investigation of the biophysicochemical properties of model spherical NPs (citrate-capped gold nanoparticles, AuNPs) of different sizes (15, 40, and $80 \mathrm{~nm}$ ) upon incubation with two widely used cellular media: DMEM-high glucose (Dulbecco Modified Eagle's Medium) and RPMI-1640 (Roswell Park Memorial Institute medium), supplemented with the protein source FBS (fetal bovine serum). Such media are exploited for most cell cultures and strongly vary for aminoacids, glucose, and salts composition (as reported by manufacturers' specifications). A range of spectroscopic, electrophoretic, and microscopic techniques were applied in order to describe the biomolecular entities formed by dispersing the differently sized metallic NPs in the cellular culture media. In particular, our efforts were directed to characterize protein corona composition, exchanging kinetics of different protein classes, along with the physical status of AuNPs in terms of agglomeration/aggregation, over time. Notably, we found that DMEM elicits a large time-dependent protein corona formation, whereas RPMI is characterized by different kinetics and a reduced protein corona content. Once separated from the excess of serum in the medium so- lution, proteins/NP complexes were also investigated by means of sodium dodecyl sulfate polyacrylamide gel electrophoresis (SDS-PAGE) and mass spectrometry analyses. Our results revealed important differences in these evolving nanobioentities showing that, despite the presence of identical AuNPs, suspending media elicit the formation of different hybrid bionanostructures that, in turn, may exert different biological effects in interacting with cells. To assess such hypothesis, we performed viability assays on models cell lines, namely HeLa (human epithelial cervical cancer cell line) and U937 (human leukemic monocyte lymphoma cell line), cultured both in DMEM and RPMI, in the presence of AuNPs. Interestingly, we detected remarkable changes in cell viability as a function of the nanobioentities formed in the two media. AuNPs uptake and cellular distribution were addressed by applying an interesting label-free tracking method, based on 2-photon confocal microscopy.

\section{RESULTS AND DISCUSSION}

To have a comprehensive characterization of the physicochemical properties of synthesized AuNPs, to be used for in vitro cellular tests, size distributions and dispersion characteristics were determined by means of transmission electron microscopy (TEM), UV-vis absorption spectroscopy, dynamic light scattering (DLS), and Z-potential. Figure 1 reports detailed information regarding morphology, particles dispersion, and surface charge for each of the differently sized $(15,40$, and $80 \mathrm{~nm}$ ) AuNPs, dispersed in ultrapure water. In particular, each size of NPs shows a spherical morphology with 


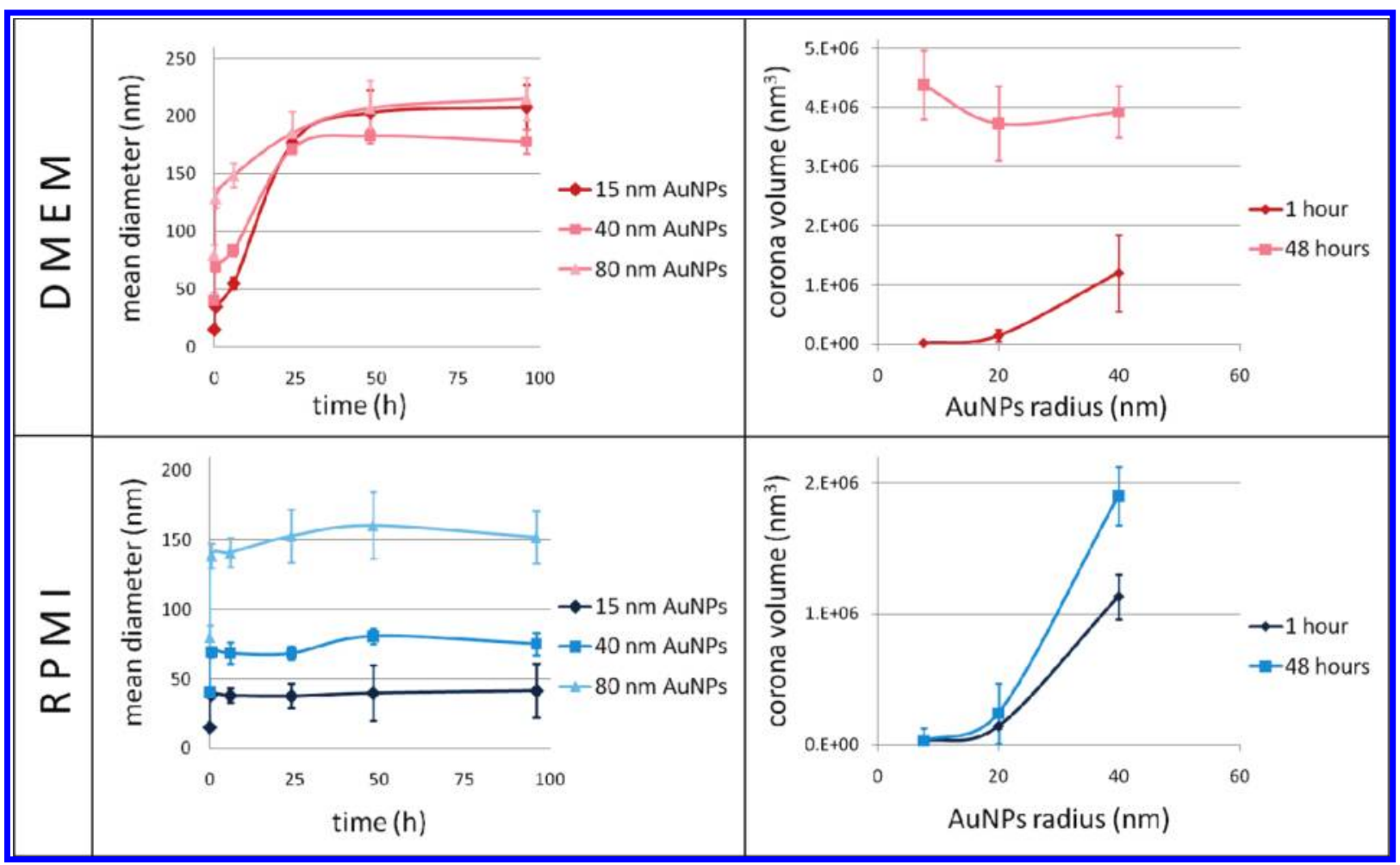

Figure 2. DLS analyses of 15, 40, and $80 \mathrm{~nm}$ AuNPs suspended in DMEM (top) and RPMI (bottom) with $10 \%$ FBS, at $37{ }^{\circ} \mathrm{C}$, over time. (Left panels) time-dependent evolution of protein corona in the two cellular media; (right panels) protein corona volume vs AuNPs radius at two elapsed times of incubation ( 1 and $48 \mathrm{~h}$ ); $48 \mathrm{~h}$ corresponds to the plateau phase of the plots on the left.

quite narrow size distribution (Figure 1). Accordingly, UV-vis absorption spectra (Figure 1B) indicate that, with increasing size, the plasmon absorption maximum shifts to longer wavelengths. ${ }^{27}$ DLS analyses (Figure 1C) confirm the good monodispersion of the AuNPs (the measured polydispersion indexes, Pdl, are lower than 0.1 for all NPs samples), consistent with TEM (Figure $1 \mathrm{E}-\mathrm{G}$ ) and spectroscopic data. DLS experiments indicate well-suspended NPs, with no detectable aggregation phenomena after dispersion in water. Zetapotential analyses (Figure 1D) show values between -43.0 and $-31.8 \mathrm{mV}$, indicating stable, negatively charged AuNPs.

Characterization of NPs interaction with cellular media was performed by suspending freshly synthesized batches of AuNPs in RPMI and DMEM supplemented with $10 \%$ of FBS (see Experimental Section). DLS experiments were carried out in the presence and absence of NPs, at physiological temperature $\left(37^{\circ} \mathrm{C}\right)$, over time. Results show that all the differently sized NPs increased their hydrodynamic diameters in the two media, until reaching a plateau phase (Figure 2, left). However, the plateau values and kinetics strongly differ in DMEM and RPMI suspensions. In particular, for all sizes, the hydrodynamic diameter of AuNPs suspended in RPMI show an abrupt increase after $1 \mathrm{~h}$ of incubation, followed by a constant behavior over time (experimental data of DLS analyses within the first $1 \mathrm{~h}$ are reported in Supporting Information, Figure S1). Such a diameter increase appears to be proportional to the particles di-

www.acsnano.org mension. On the other hand, the mean diameter of AuNPs in DMEM reaches higher values (about $200 \mathrm{~nm}$ ) independent of NP size, though with a slower kinetics. The size increase can be ascribed to protein corona formation around the metallic NPs, because no evidence of aggregation is found in the DLS spectra, which show rather monodispersed peaks over time (Supporting Information, Figure S2). The absence of NP agglomerates/ aggregates in the two media was also confirmed by TEM analyses (Figure S3). Moreover, control experiments in cellular media containing FBS without NPs showed no significant protein aggregation (Figure S4). Figure 2 (right) reports the time dependent evolution of the protein corona volume in the two culture media, as a function of the radius of the NPs. This analysis shows that the RPMI induced protein corona strongly increases with the particles' radius, after both 1 and $48 \mathrm{~h}$ of incubation (bottom). In DMEM the trend was completely different at $48 \mathrm{~h}$ (top). In this latter case, in fact, no significant dependence of biomolecular corona on the radius of the NPs was observed, indicating that protein clusters deposition onto the metal surfaces in DMEM was almost unaffected by the particles dimensions with increasing incubation time. These results demonstrate that protein adsorption onto the surface of the NPs is strongly affected by the suspending medium.

Protein corona in the two media was further characterized by UV-vis absorption. AuNPs typically exhibit a peculiar localized surface plasmon resonance (LSPR) 


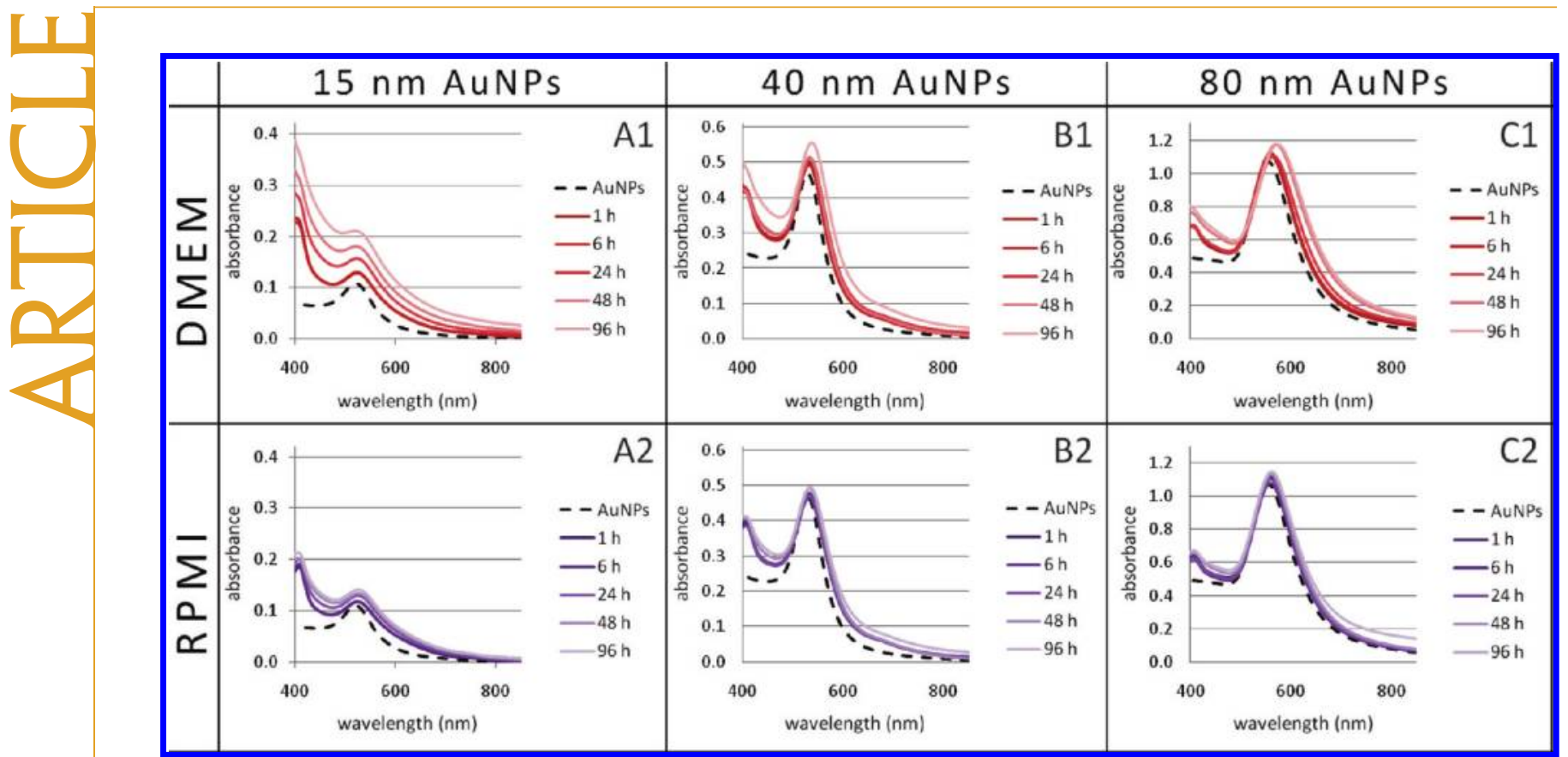

Figure 3. Absorption spectra of $15 \mathrm{~nm}$ (A1 and A2), $40 \mathrm{~nm}$ (B1 and B2), and $80 \mathrm{~nm}$ (C1 and C2) AuNPs suspended in DMEM or RPMI (10\% FBS) at $37^{\circ} \mathrm{C}$, after $1,6,24,48$, and $96 \mathrm{~h}$, as compared to the AuNPs suspended in water at the same concentration.

band, whose position and intensity depend on NP size, shape, and dielectric constant of the medium in close proximity to the surface of the nanoparticles. ${ }^{28}$ This spectral feature can thus be exploited to finely probe chemical or biological molecules adsorption onto the NP surface. ${ }^{29-31}$ As shown in the graphs (Figure 3), DMEM-suspended NPs exhibit both a slight red shift and an increase of band intensity over time. Such spectral changes were larger than those observed in RPMI, suggesting that DMEM promotes a more abundant and stable protein corona clustering onto the NPs metal surface (an additional analysis of the temporal variation of LSPR peaks is reported in Supporting Information, Figure S5). These data are in line with DLS analyses (Figure 2) and further support the strong role of the suspending medium to influence protein-nanostructure interactions.

The factors affecting protein corona formation are several (such as protein-NPs, protein-protein, protein-media components, and NPs-media components interactions), owing to the vast complexity of the two cellular media, and a cooperative mechanism of different parameters may be envisaged (see Supporting Information, Figure S6 and relative comments).

The particular protein dressing of AuNPs and the peculiar exchange kinetics of proteins onto the metallic surface can modulate interparticle interactions. ${ }^{32,33}$ Such kinetics may drive certain agglomeration mechanisms, leading, in turn, to a complex size distribution of protein-coated NPs, still well-dispersed in solution. To deepen the physical status of protein-coated AuNPs in the two media, we exploited the PRLS (plasmon resonance light scattering) technique, a very sensitive tool to monitor interparticle interactions induced by biomacromolecules. ${ }^{34}$ In particular, interparticle interac- tions of AuNPs generate an enhanced plasmon resonance light-scattering peak at about $550 \mathrm{~nm} .^{34,35}$ Experimental data revealed a slight time-dependent increase of the plasmon scattering signal in both media (Figure 4). Such modest increase suggests the absence of significant aggregation phenomena in the two solutions, in line with the above spectroscopic results and TEM analyses. ${ }^{36}$ However, in the case of $15 \mathrm{~nm}$ AuNPs, the increase of the scattering signal was higher, possibly indicating the presence of some agglomeration process of the smaller particles in the two media (especially in RPMI), not detectable by less sensitive techniques such as DLS or UV-vis. In any case, we found that PRLS enhancement was always larger for RPMI than DMEM, revealing a higher tendency of RPMI in promoting interparticles interactions.

In the attempt to isolate and characterize protein/NP complexes as a function of NPs sizes and suspending media, time dependent monitoring of protein coronas was also assessed ex situ, out of cellular medium solution, by SDS-PAGE and MS. After centrifugation, we collected pellets of two specific temporal points (namely, 1 and $48 \mathrm{~h}$ ) corresponding to the starting and plateau phases of protein corona formation (see Figure 2). Such procedure likely reproduces off-line snapshots of NPs corona in solution. Many methods have been applied to investigate protein corona, all showing advantages and limits. Among these, centrifugation method has been recently recognized to provide useful information on what is usually called "hard protein corona". ${ }^{19}$ Therefore, once isolated by centrifugation and accurate washing, we analyzed the resulting stable protein/NP complexes by SDS-PAGE and MS analyses. To compare the different protein electrophoretic lines, we incubated batches of AuNPs at concentrations giving con- 


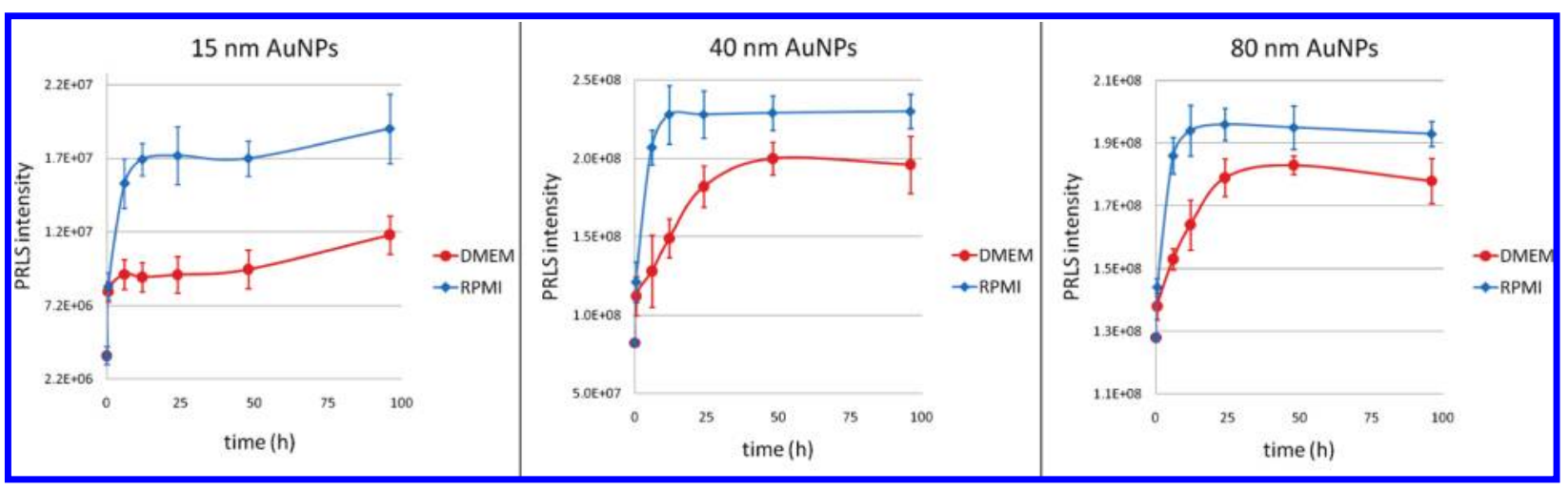

Figure 4. PRLS intensity (at $550 \mathrm{~nm}$ ) vs time of incubation of 15, 40, and $80 \mathrm{~nm}$ AuNPs suspended in DMEM and RPMI (10\% FBS), at 37 ${ }^{\circ} \mathrm{C}$.

stant values of the total surface area of the NPs for all the sizes (like in the previous experiments). Representative gels (Figure $5 A, B$ ) show rich protein profiles for all the AuNP sizes in both the cell culture media. Densitometric analyses confirmed that, whereas at $1 \mathrm{~h}$ of incubation the total amount of adsorbed proteins roughly increases as a function of the nanoparticle sizes, with no particular differences between the two media, after $48 \mathrm{~h}$ (plateau phase), DMEM incubated AuNPs produced a higher total amount of hard protein coronas (this was also demonstrated by TEM imaging, see Supporting Information, Figure S7). These data are in good agreement with our results obtained by means of in situ characterization (i.e., in medium solutions, see above), supporting the recent idea that inspection of protein corona by separation methods may be useful to study the complex dynamics underlying proteins/NP interactions in solution. ${ }^{33}$ In Figure 5 panels $C$ and D we report the relative distribution of protein classes as a function of NP size and cellular media. Interestingly, gel images and densitometric analyses revealed that protein patterns strongly differ with respect to the relative distribution of serum proteins (Figure 5C,D; red histograms). In particular, bands belonging to $1-9$ classes $(280-100$ $\mathrm{KDa}$ ) were grouped in the high molecular weight proteins (HMW), 10-21 classes (100-35 kDa) in the medium molecular weight proteins (MMW), bands 22-31 (35-10 kDa) were in the low molecular weight (LMW) range. On the basis of their electrophoretic mobility and mass, we can argue that most represented proteins of FBS, such as BSA and Fibrinogen, are in 12-15 classes range. We can observe that such species are not predominantly represented in the gel lines of protein coronas. This suggests that, in the serum mixture, complex mechanisms of competition among highly affine protein molecules lead NPs to act as concentrators of less abundant serum proteins, while BSA and Fibrinogen only partially interact with the NP surface (Figure 5). ${ }^{18,21,36-39}$ Such an effect was found to be similar in both the cellular media, with a slight dependence on the NP size. Moreover, histograms relative to the band intensity of the three grouped classes (i.e., HMW, MMW, and LMW) revealed further differences in the kinetics of proteins distribution in the hard protein corona (Figure $5 \mathrm{E}, \mathrm{F})$. In particular, at $1 \mathrm{~h}, \mathrm{HMW}$ and LMW proteins are strongly up-represented with respect to fetal bovin serum (control), while MMW proteins are down represented (Figure 5E). After $48 \mathrm{~h}$, the intensity of MMW protein classes increases at the expense of the LMW proteins (Figure 5F), while layers composed by high molecular weight protein do not show particular changes over time..$^{32,33,38-40}$ This suggests that this latter class is less susceptible than the other groups to the dynamic protein exchange occurring during the formation of protein corona. Since increasing evidence suggests that the specific molecular composition of protein corona may play a fundamental role in triggering biological responses, ${ }^{19-21,36}$ the above characterizations are of particular interest.

Protein corona composition was analyzed by LC-MS/MS. The main identified protein species adsorbed onto the metallic NPs surfaces (listed in Table S8, Supporting Information) are found to be important proteins involved in key biological processes, such as transport and trafficking (apolipoprotein A1, transferrin, vitamin D-binding protein, etc.), blood coagulation (protein C inhibitor, antithrombin III, coagulation factor $\mathrm{V}$, etc.) and tissue development (fibulin 1, periostin, thrombospondin-1, galectin 3 binding protein, etc.). ${ }^{19,38,39,41}$ On the basis of their molecular weight, such proteins are present especially in the MMW and LMW groups. Hence, they may be susceptible to the exchange kinetics evidenced in Figure $5 \mathrm{E}$ and F. Such changes, occurring within the experimental temporal windows typical of cell viability tests, might differently affect the outcomes of nanotoxicity tests, due to the specific biological influence of protein coronas.

As a final test, we investigated whether such dynamic protein/NP complexes may account for different biological responses in cells. We performed a classical viability assay (WST-8 assay) by using two different cellular lines (HeLa and U937) cultured both in DMEM and RPMI, in the presence of increasing dosage of AuNPs (we selected, as an example, the $15 \mathrm{~nm}$ size). Before 


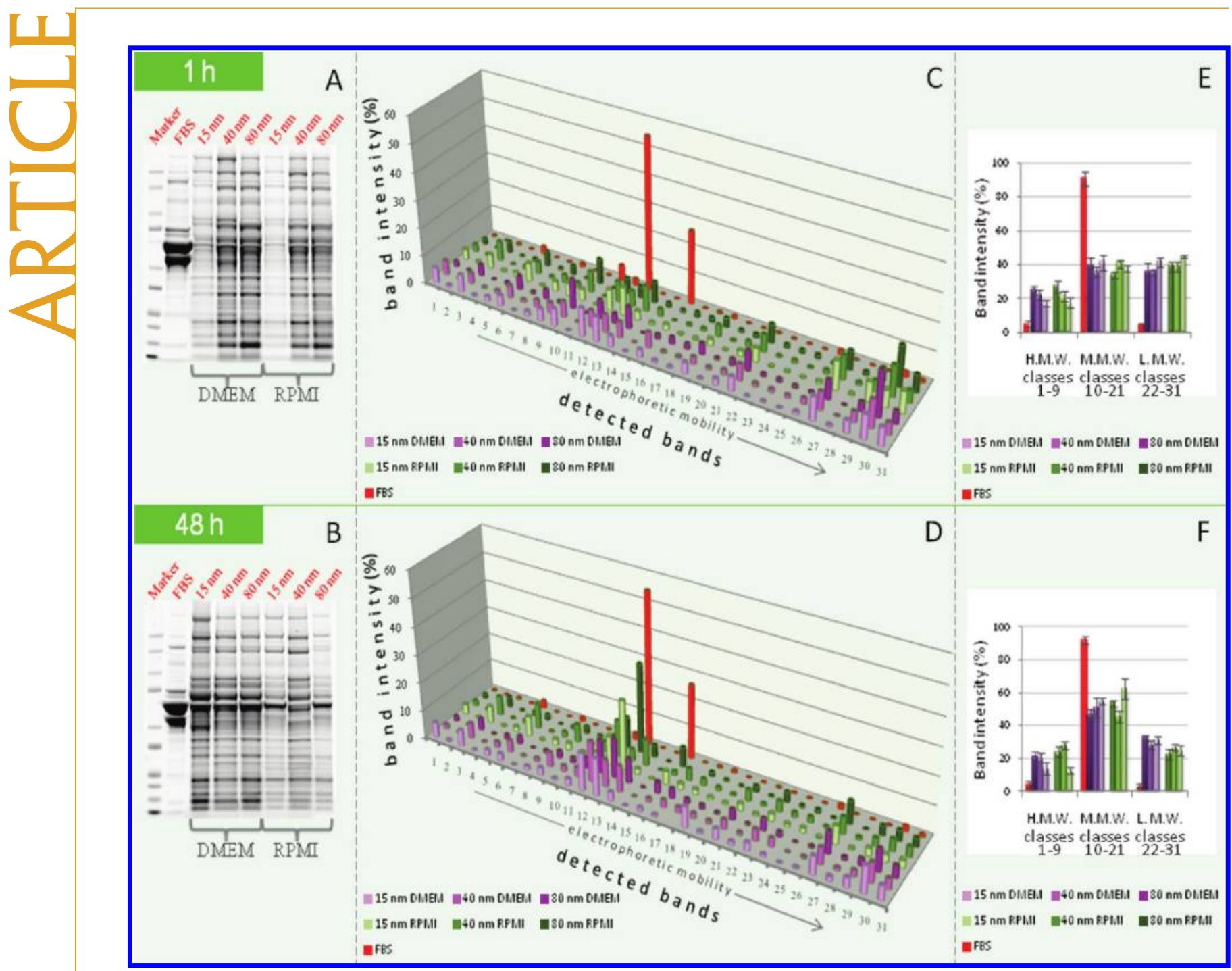

Figure 5. (A, B) Representative SDS-PAGE of protein corona obtained from 15, 40, and $80 \mathrm{~nm}$ AuNPs, after incubation with DMEM and RPMI at $37^{\circ} \mathrm{C}$ for $1 \mathrm{~h}(\mathrm{~A})$ and $48 \mathrm{~h}(\mathrm{~B})$. (C, D) Densitometric analyses of 1 and $48 \mathrm{~h}$ gels; 31 gel bands were experimentally detected as single peaks, whose intensity percentages are plotted $v s$ band electrophoretic position. The obtained histograms depict the relative distribution of protein classes as a function of NP size and cellular media. Classes 1-31 are ranged starting from high to low molecular weights. Reported data are the mean values of three independent experiments. (E, F) Plot of band intensity vs pooled gel bands, that were grouped as reported: 1-9 as HMW, 10-20 as MMW, and 21-31 as LMW, according to the experimental position. Data are reported as mean values of three independent experiments.

testing, possible interference phenomena between AuNPs and both WST-8 reagent and product (formazan) were evaluated (see Experimental Section), finding out no significant interferences in the AuNPs concentration range used here (data not shown). Also, we verified by trypan blue exclusion dye method that both HeLa and U937 correctly grow in DMEM and RPMI (they exhibited the same growth rate in the two media). Figure 6 shows a moderate toxic effect of AuNPs on both cell lines, but it is worth noting that a clear variation of the cell viability between the two cellular media can be observed. Such a discrepancy may be ascribed to the different protein coronas dynamically formed in the two media (see above). In fact, AuNPs show more adverse effects in RPMI than in DMEM, suggesting that RPMI-treated NPs, characterized by a less abundant protein corona, exert a stronger toxicity on cells. This finding was supported by three additional assays, namely
LDH leakage assay (useful to determine possible membrane damages), quantitative necrosis/apoptosis assay by flow cytometry, and TUNEL assay (to detect possible DNA fragmentation) (see Supporting Information, Figures S9 and S10). All the three additional tests confirmed the findings of toxicity of AuNPs. Moreover, both the quantitative analyses (i.e., LDH and apoptosis/necrosis assays) demonstrated the higher toxicity of AuNPs in RPMI as compared to those in DMEM, in line with the WST assay reported above.

We assessed AuNPs uptake and cellular distribution in both media by confocal microscopy. In Figure 7, we report representative images that display AuNPs uptake by HeLa cells. Interestingly, metallic nanoparticles were detected by means of a label-free method that exploits the intrinsic photoluminescence of gold, generated upon 2-photon absorption from a near-infrared ultrafast laser. ${ }^{42,43}$ Importantly, such an imaging 


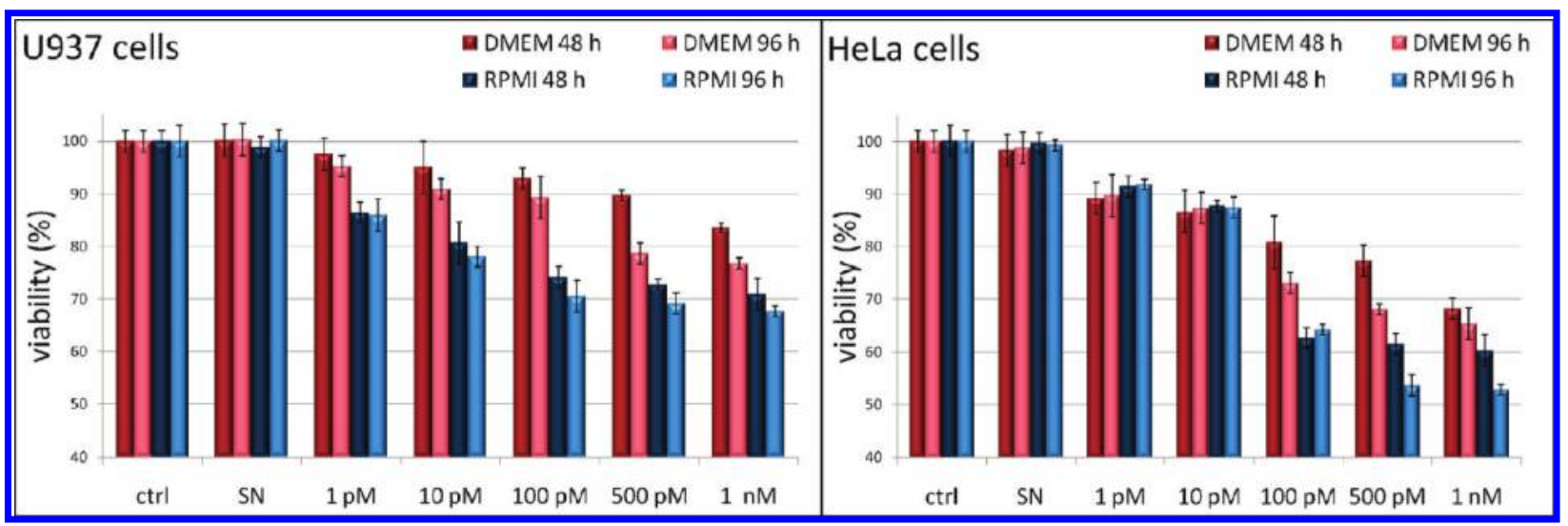

Figure 6. WST-8 proliferation assays of HeLa and U937 cells, cultured both in high glucose-DMEM and RPMI-1640. Cells were incubated with increasing concentrations of $15 \mathrm{~nm}$ AuNPs and at different incubation times. Results are reported for 48 and $96 \mathrm{~h}$. Ctrl represents the negative control; SN is the supernatant obtained after incubation and centrifugation procedures (see Experimental Section for details).

technique allows for label-free NPs cellular tracking, thus avoiding possible artifacts due to the release of free dye in cells. Figure 7 panels A and B show that NPs (green spots) appear distributed in the cytoskeleton, mostly in the perinuclear region (nuclei and cytoskele- ton are in blue and red, respectively), with a similar behavior in the two media. In Figure 7C and D, living cells were imaged by staining nuclei and lysosomal compartments (blue and red, respectively). We found that AuNPs were actively internalized by cells in a quite simi-
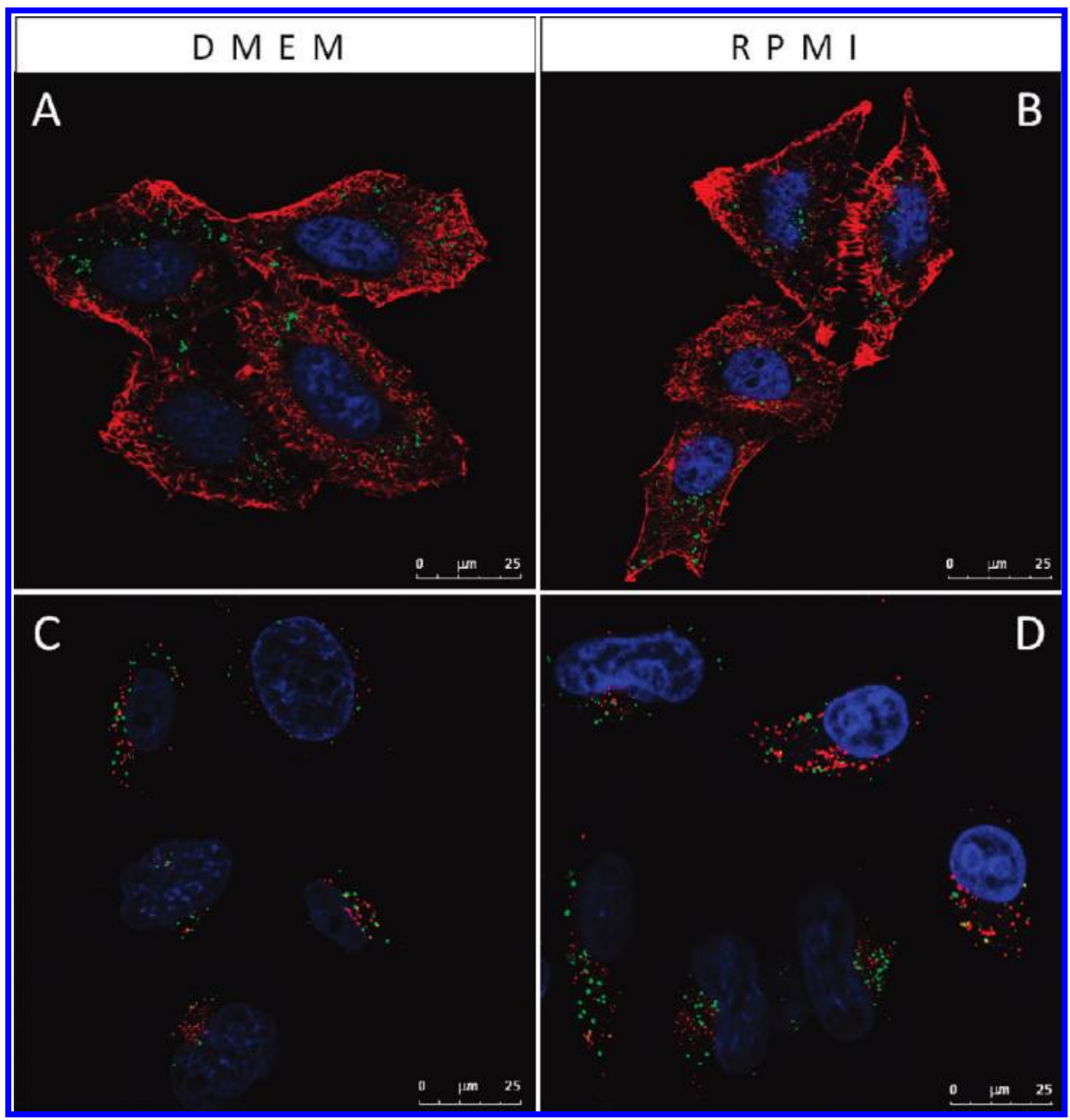

Figure 7. Representative confocal images of HeLa cells cultured in DMEM $(A, C)$ and RPMI $(B, D)$ in the presence of 100 pM AuNPs. Panels A and B show representative images of fixed cells: nuclei stained by Hoechst 33258 (blue), actin cytoskeleton labeled by Alexa Fluor 488 phalloidin (red), and unlabeled AuNPs (green) imaged by two-photon microscopy. Panels C and $D$ report representative images of living cells: nuclei stained by Hoechst 33342 (blue) and lysosomal compartments stained by LysoTracker (red). AuNPs (green) were imaged as described above. 
lar manner, being predominantly localized into lysosomes in both DMEM and RPMI (no particular differences were evidenced for U937 cells, so that data were not reported). Confocal analyses, however, could not provide a quantitative description of AuNP uptake by cells, so that it is possible that the different toxicity observed in Figures 6 and S9 in the two media is partially due to a different cellular uptake capability of the two differently sized hybrid nanobioentities (we observed that the smaller protein-corona-coated AuNPs induced higher toxicity). Such different cellular uptake in the two media was demonstrated by ICP-AES results (Supporting Information, Figure S11), which show that the overall amount of internalized gold by the cells was significantly higher in RPMI than in DMEM. These differences clearly explain the different cellular toxicity observed in the two media.

\section{CONCLUSIONS}

Our results demonstrate that the dynamics of protein-NP interactions are differently mediated by the different composition of common cellular media (i.e., DMEM and RPMI supplemented with bovine serum), which are the liquid environments where NPs encounter cells in in vitro studies. DLS, UV-vis absorption, and PRLS data, obtained by in situ studies, revealed interesting effects on the physical status of the NPs mediated by DMEM or RPMI. In particular, DMEM induced a more abundant and quite stable protein corona on different sizes of AuNPs as compared to RPMI. Such findings were also confirmed by ex situ analyses, in which the strongly adsorbed proteins onto metal surfaces were analyzed by SDS-PAGE and MS. Importantly, the different formation of proteins/NP complexes mediated by liquid environment impacts on cellular response. Thereby, to evaluate NPs dose-dependence toxicity in in vitro tests, all experimental parameters, comprising the choice of the cellular medium, as well as the origin and preparation of serum, should be carefully taken into account with the aim to design standardized protocols.

\section{EXPERIMENTAL SECTION}

AuNPs Synthesis and Characterization. All glassware and the magnetic stir-bar were washed thoroughly with aqua regia $(\mathrm{HCl}$ and $\mathrm{HNO}_{3}$ in a 3:1 volumetric ratio). Colloidal $15 \mathrm{~nm}$ sodium citratecapped AuNPs were synthesized by the classical Turkevich-Frens method, ${ }^{44,45}$ using trisodium citrate as reducing agent in aqueous solution. Briefly, $150 \mathrm{~mL}$ of $0.25 \mathrm{mM}$ aqueous solution of $\mathrm{HAuCl}_{4}$ (Sigma-Aldrich) in a two-neck roundbottom flask, with a condenser and a thermometer, was heated to boiling with a heating mantel while stirring. Then, $2.8 \mathrm{~mL}$ of $1 \%$ aqueous solution of sodium citrate (Sigma-Aldrich) was added. The solution was kept gently boiling for $30 \mathrm{~min}$ and then slowly cooled down when a red wine color appeared. AuNPs of 40 and $80 \mathrm{~nm}$ were prepared according to a two-step seed-mediated method ${ }^{46}$ which allows the enlargement of 15 $\mathrm{nm}$ AuNPs (seeds) for the property of $\mathrm{NH}_{2} \mathrm{OH}$ to efficiently reduce $\mathrm{Au}^{3+}$ to bulk metal in the presence of a Au surface. ${ }^{47}$ The synthesis was performed by adding $2 \mathrm{~mL}$ of aqueous $40 \mathrm{mM}$ hydroxylamine sulfate (Sigma-Aldrich) and different numbers of gold seeds into $200 \mathrm{~mL}$ of aqueous solution. The solution was kept under vigorous stirring and then $25 \mathrm{~mL}$ of $2 \mathrm{mM}$ aqueous solution of $\mathrm{HAuCl}_{4}$ was dropwise added to the seeds solution (1 $\mathrm{mL} \mathrm{min}^{-1}$ ) After the addition of $\mathrm{HAuCl}_{4}$ solution was finished, the mixture was stirred for a further $30 \mathrm{~min}$ and then $12 \mathrm{~mL}$ of $1 \%$ aqueous solution of trisodium citrate was injected to stabilize AuNPs by the weak capping effect of such a chemical. To minimize the presence of solvent and unreacted reagents all the solutions were immediately centrifuged for $15 \mathrm{~min}$ to isolate 15, 40, and $80 \mathrm{~nm}$ AuNPs, respectively. Immediately after, pelletted NPs were suspended in $150 \mathrm{~mL}$ of ultrapure water. Before their use, NPs were filtered using a $0.22 \mu \mathrm{m}$ syringe filters (Fluoropore PTFE membrane, purchased form Millipore Corp.) under a laminar flow biological safety cabinet, to ensure sterility.

To obtain essential information on size and shape of the AuNPs, TEM images were carried out. The 300 mesh carboncoated copper grid was cast with a few drops of citrate-capped AuNPs and vacuum-dried. TEM images of each sample were collected using a JEOL Jem 1011 transmission electron microscope with an accelerating voltage of $100 \mathrm{kV}$. UV-vis spectra were recorded using a Cary 300 Bio double-beam spectrophotometer at a $300 \mathrm{~nm} / \mathrm{min}$ scanning rate from 400 to $850 \mathrm{~nm}$. The AuNP concentrations were measured using the molar extinction coefficients measured at the wavelength of the maximum absorption. ${ }^{48}$ Further characterizations were performed by dynamic light scattering (DLS) and zeta-potential analyses using a Zetasizer Nano-ZS instrument (Malvern Instruments) equipped with a $4.0 \mathrm{mV} \mathrm{He}-\mathrm{Ne} 633 \mathrm{~nm}$ laser.

Dynamic Light Scattering (DLS), UV-vis absorption (UV-vis) and Plasmon Resonance Light Scattering (PRLS) of AuNPs upon Incubation with Cell Culture Media. Cell culture media DMEM high glucose (Dulbecco's Modified Eagle Medium) and RPMI-1640 (Rosenthal Park Memorial Institute) from Gibco Invitrogen (www.invitrogen.com, catalogue no. 32404-014 and 31053-02 for RPMI and DMEM, respectively) were supplemented with $10 \%$ of fetal bovin serum (FBS) (Gibco Invitrogen) as protein source, with $50 \mu \mathrm{M}$ glutamine (Gibco), $1 \mathrm{mM}$ sodium pyruvate (Gibco), $100 \mathrm{U} / \mathrm{mL}$ penicillin, and $100 \mathrm{mg} / \mathrm{mL}$ streptomycin (Invitrogen). Protein content was quantified by using the Bradford assay (Biorad) following the manufacturer's instructions. Each size of AuNPs was incubated at $37{ }^{\circ} \mathrm{C}$ with the two cell culture media ( $100 \mathrm{~mL}$ of RPMI or DMEM $10 \%$ FBS presenting a total amount of proteins of $3.3 \mathrm{mg} /$ $\mathrm{mL}$ ) using concentrations that give the same amount of total surface area among the different NPs, namely $0.360,0.050$, and $0.013 \mathrm{nM}$ for 15,40 , and $80 \mathrm{~nm}$, respectively. In any case, we performed the same DLS experiments by normalizing the NP concentrations with respect to their mass, finding no detectable differences in protein corona, because of the large excess of proteins in solution compared to the AuNPs. DLS and UV-vis spectra were taken at different elapsed times of incubation, namely 1, 6, 24, 48, and 96 h. PRLS spectra were acquired under the same experimental conditions by a FluoroLog 3 fluorescence spectrometer (Jobin Yvon) by scanning simultaneously the excitation and emission monochromators at $\Delta \lambda=0 \mathrm{~nm}$ from 400 to $800 \mathrm{~nm}$.

SDS-PAGE of Protein Corona and Identification by Using Mass Spectrometry. Protein corona was analyzed by SDS-PAGE in three independent experiments to ensure reproducibility. AuNPs of 15 40 , and $80 \mathrm{~nm}$ were incubated with supplemented DMEM and RPMI (containing $10 \%$ of FBS) for 1,12 , and $48 \mathrm{~h}$ and then centrifuged for $15 \mathrm{~min}$. The obtained pellets were continuously washed with sterile phosphate buffer saline (PBS) (Sigma) until no proteins were detectable in the supernatant by Bradford assay. Final pellets were resuspended in buffer, in order to detect AuNPs concentration by spectrophotometric measurements. Then, all the quantified solutions, containing the different sizes of AuNPs, were mixed with sample buffer (NuPAGE LDS sample buffer 4X, Invitrogen) and 0.2 M dithiothreitol (DTT) (Invitrogen) to obtain concentrations giving constant values of total surface 
area for all NPs. Before loading onto $8-16 \%$ NuPAGE 1D gels (Invitrogen), samples were heated at $70{ }^{\circ} \mathrm{C}$ for $10 \mathrm{~min}$. After electrophoresis, gels were stained with Gelcode blue comassie (Pierce) following manufacturer's instructions, imaged by means of a laser-based imaging scanner (Typhoon 9400; GE Healthcare) and digitized using ImageQuant software (GE Healthcare). Quantification of the bands intensities was carried out by densitometric analysis using ImageQuant software (GE Healthcare). Specifically after the editing of the lanes, automatic background subtraction was performed by a rolling ball tool and the bands detection was carried out manually. The bands were quantified as band intensity and expressed as band \% (i.e., relative to the total intensity of all the bands in the lane). Data were expressed as mean \pm standard deviation (SD). Differences in band \% were considered statistically significant performing a Student's $t$ test with a $p$-value $<0.05$. Bands of interest from SDS/PAGE gels were excised from the gel and washed in $50 \mathrm{mM}$ ammonium bicarbonate $\mathrm{pH} 8.0$ in 50\% acetonitrile to a complete destaining. The gel pieces were resuspended in $50 \mathrm{mM}$ ammonium bicarbonate $\mathrm{pH} 8.0$, reduced with $10 \mathrm{mM}$ DTT at $56^{\circ} \mathrm{C}$ for $45 \mathrm{~min}$ and alkylated with a $55 \mathrm{mM}$ solution of iodoacetamide in the same buffer for $30 \mathrm{~min}$ at room temperature in the dark. The excess of reagent was discarded and the gel pieces were washed several times with the buffer, resuspended in $50 \mathrm{mM}$ ammonium bicarbonate and incubated with $100 \mathrm{ng}$ of trypsin for $2 \mathrm{~h}$ at $4{ }^{\circ} \mathrm{C}$ and overnight at $37^{\circ} \mathrm{C}$. The supernatant containing peptides was removed and the remaining gel pieces were washed with acetonitrile in order to extract the peptides still present in the gel. These two fractions were then collected and freeze-dried. The resulting peptide mixtures were analyzed by electrospray liquid chromatography mass spectrometry (LC MS/MS) using the LC/MSD Trap XCT Ultra (Agilent Technologies, Palo Alto, CA) equipped with a 1100 HPLC system and a chip cube (Agilent Technologies). After loading, the peptide mixture ( $7 \mu \mathrm{L}$ in $0.5 \%$ trifluoroacetic acid) was first concentrated at $4 \mu \mathrm{L} / \mathrm{min}$ in a $40 \mathrm{~nL}$ enrichment column (Agilent Technologies chip), with $0.1 \%$ formic acid as the eluent. The sample was then fractionated on a C18 reverse-phase capillary column $(75 \mu \mathrm{m} \times 43 \mathrm{~mm}$ in the Agilent Technologies chip) at a flow rate of $300 \mathrm{~nL} / \mathrm{min}$, with a linear gradient of eluent $B(0.1 \%$ formic acid in acetonitrile) in A ( $0.1 \%$ formic acid) from 7 to $50 \%$ in $35 \mathrm{~min}$. Elution was monitored on the mass spectrometers without any splitting device. Peptide analysis was performed using data-dependent acquisition of one MS scan ( $\mathrm{m} / \mathrm{z}$ range from 400 to $2000 \mathrm{Da} / \mathrm{e}$ ) followed by MS/MS scans of the three most abundant ions in each MS scan. Dynamic exclusion was used to acquire a more complete survey of the peptides by automatic recognition and temporary exclusion ( $2 \mathrm{~min}$ ) of ions from which definitive mass spectral data had previously been acquired. Moreover, a permanent exclusion list of the most frequent peptide contaminants (keratins and trypsin peptides) was included in the acquisition method in order to focus the analyses on significant data. Mass spectral data obtained from the LC-MS/MS were used to search a nonredundant protein database using an in house version of the Mascot 2.1 (Matrix Science, Boston, MA, USA) software. Peptide mass values and sequence information from LC-MS/MS experiments were used in the MS/MS ion search, taking into account the carbamidomethylCys as fixed modification, a precursor ion, and a fragment ion mass tolerance of \pm 600 ppm and $0.6 \mathrm{Da}$, respectively.

Cell Culture. HeLa (IST cell factory Genova, Italy) cells were routinely cultivated in high glucose DMEM with $50 \mu \mathrm{M}$ glutamine, supplemented with $10 \%$ FBS, $100 \mathrm{U} / \mathrm{mL}$ penicillin, and 100 $\mathrm{mg} / \mathrm{mL}$ streptomycin. Cells were incubated in a humidified controlled atmosphere with a $95 \%$ to $5 \%$ ratio of air/ $\mathrm{CO}_{2}$, at $37{ }^{\circ} \mathrm{C}$. Medium was changed every 3 days. Subconfluent cultures were split once per week, using 1X trypsin/EDTA (Invitrogen). A subculture of HeLa cells was gradually adapted in RPMI 1640 medium (Gibco) with the same medium supplementation. ${ }^{49}$ The opposite procedure was actuated for U937 (IST cell factory Genova, Italy), routinely cultivated in RPMI $1640 .^{50}$ To ensure cell viability in both media, growth assays were performed on both cell lines using trypan blue exclusion dye method (Sigma) and direct counts in a light microscope, by means of an hemocytometer. The results clearly indicated that the two cell culture media do not affect cell growth.
WST-8 Cytotoxicity Assay. The metabolic activity of HeLa and U937 cell cultures was determined after 24, 48, 72, and $96 \mathrm{~h}$ of exposure to $15 \mathrm{~nm}$ AuNPs, using a standard WST-8 assay (Sigma); $96 \mathrm{~h}$ represents the maximum time in which cell viability is not influenced by deficiency of nutrients. Assays were performed in 96 multiwell microplates (Sarstedt) for each time $(24,48,72$, $96 \mathrm{~h})$. Cells were seeded in microplates at a density of 5000 cells/ well and cultured for $24 \mathrm{~h}$ in a humidified atmosphere at $37^{\circ} \mathrm{C}$ and $5 \% \mathrm{CO}_{2}$ to obtain a confluent monolayer. Different amounts of AuNPs dispersed in cell culture medium stock solutions were added at the single well obtaining final AuNPs concentrations of $1,10,100$, and $500 \mathrm{pM}$ and $1 \mathrm{nM}$. As a positive control for cytotoxicity, cell were incubated with $5 \%$ DMSO. We evaluated also the potential cytotoxic effect of AuNP solvent. We centrifuged AuNP solutions at the maximum concentration investigated (1 $\mathrm{nM})$, and the supernatant was thus added to the cell seeded into microplates to characterize its intrinsic cytotoxic potential. Eight replicates were forecasted for each investigated point considering also controls (untreated cells) and blanks constituted by the addition of the medium only. A $10 \mu \mathrm{L}$ aliquot of Cell Counting Reagent WST-8 (Sigma) was added to each well. The 96-well microplates were placed in a humidified atmosphere of $5 \% \mathrm{CO}_{2}$ and $37^{\circ} \mathrm{C}$ and incubated for $3 \mathrm{~h}$. Subsequently, the orange WST-8 formazan product was measured by using Fluo Star Optima (BMG LABTECH) microplates reader at a wavelength of $460 \mathrm{~nm}$. Data were collected by Control Software and elaborated with MARS Data Analysis Software (BMG LABTECH). To express the cytotoxicity, the average absorbance of the wells containing cell culture medium without cells was subtracted from the average absorbance of the solvent control, 5\% DMSO or AuNPs treated cells. The percentage cell viability was calculated using the following equation:

$$
\frac{\text { absorbance }_{\text {treated }}}{\text { absorbance }_{\text {control }}} 100
$$

Data were expressed as mean $\pm \mathrm{SD}$. Differences in cell proliferation (WST-8) between cells treated with AuNPs and the control were considered statistically significant performing a Student's $t$ test with a $p$-value $<0.05$.

Interference of AuNPs with the WST-8 assay. Following the observations reported by Park and colleagues, ${ }^{15}$ two different WST-8 interference tests were performed. The first one was directed to assess if the optical properties of the AuNPs (light scattering and/or absorption) interfere with the WST- 8 reagent in the concentration range used in this work. In a 96-well microplates, either 100 $\mu \mathrm{L}$ of cell culture medium or cell culture medium containing AuNPs in all the tested concentrations (1, 10, 100, and $500 \mathrm{pM}$ and $1 \mathrm{nM}$ ) was added to the wells (without cells). The plate was then placed for $24 \mathrm{~h}$ in a humidified atmosphere of $5 \% \mathrm{CO}_{2}$ and $37^{\circ} \mathrm{C}$. Following this incubation period, $10 \mu \mathrm{L}$ of Cell Counting Reagent WST-8 was added to each well, and the plate was incubated for $3 \mathrm{~h}$ in a humidified atmosphere of $5 \% \mathrm{CO}_{2}$ and $37{ }^{\circ} \mathrm{C}$. Absorbance of each well was measured as described above. Data indicated that in this concentration range no interferences were detected for AuNPs with WST-8 reagent. The second interference test was designed to determine whether AuNPs interfere with the WST-8 formazan reaction product. For this test, HeLa cells were seeded in 96-well microplates at a density of 5000 cells/well and cultured for $24 \mathrm{~h}$ at $37{ }^{\circ} \mathrm{C}$ in $5 \% \mathrm{CO}_{2}$. The following day, cell culture medium was removed from the cells and replaced by $100 \mu \mathrm{L}$ of fresh cell culture medium. Next, $10 \mu \mathrm{L}$ Cell Counting Reagent WST- 8 was added to each well. Following an incubation of $3 \mathrm{~h}$ in a humidified atmosphere of $5 \% \mathrm{CO}_{2}$ and 37 ${ }^{\circ} \mathrm{C}$, the supernatant was removed from the cells and transferred to new 96-well microplates. Subsequently, absorbance of each well was measured as described above. A $10 \mu \mathrm{L}$ portion of DMEM or RPMI freshly prepared AuNP suspension was added to the wells to a final concentration of nanoparticles identical to the previous assays, and the absorbance was determined again. Results indicated that the interference of the WST-8 product was not significant also at the highest AuNPs concentration (1 nM) (data not shown).

Confocal Microscopy Imaging. Uptake of unlabeled AuNPs in cells was tracked by confocal microscope using 2-photon lumines- 
cence of AuNPs. ${ }^{42,43}$ HeLa and U937 cells both in DMEM and RPMI were incubated with AuNPs at a final concentration of 100 pM for $24 \mathrm{~h}$ at $37{ }^{\circ} \mathrm{C}$ in $5 \% \mathrm{CO}_{2}$. The following day, cell culture medium was removed from the cells and replaced by cell medium fully supplemented without AuNPs. After $24 \mathrm{~h}$ of incubation, samples were washed with PBS pH 7.4 (Sigma), harvested, and then fixed in buffered 3.7\% formaldehyde (Sigma) for 20 min, permeabilized with $0.1 \%$ Triton X-100 (Sigma) in PBS for 5 min, and blocked in PBS, $1 \%$ BSA, and $0.01 \%$ sodium azide for 15 min. Subsequently, cells were incubated with $1 \mathrm{ng} / \mathrm{mL}$ Hoechst 33258 (Sigma) in PBS for nuclei staining, $1 \mu \mathrm{g} / \mathrm{mL}$ Alexa Fluor 488 phalloidin (Molecular Probes) for F-actin staining. After washing, all samples were mounted with Fluoromount (Sigma) on a glass coverslip to be imaged by confocal microscopy (Leica TCSSP5 AOBS). AuNPs uptaken by cells were imaged by means of the same microscope equipped with a femtosecond Ti:sapphire laser (Mai Tai, Spectra Physics, Newport). Sub-100-fs pulses of $800-n m$ light were used as the excitation source, while AuNPs 2-photon luminescence was collected between 450 and $600 \mathrm{~nm}$. To follow the cellular fate of AuNPs, HeLa and U937 cells were treated with AuNPs as mentioned above, harvested, and incubated in a DH-40i Microincubator (Warner Instruments) in close configuration, to maintain cells under constant temperature and atmospheric conditions $\left(37^{\circ} \mathrm{C}\right.$ and $\left.5 \% \mathrm{CO}_{2}\right)$. To image lysosomes, LysoTracker Red DND-99 ( $\lambda_{\text {ex }}=577 \mathrm{~nm}, \lambda_{\text {em }}=590 \mathrm{~nm}$ ) (Molecular Probes) was used, directly in the growth media, at a final working concentration of $75 \mathrm{nM}$. For in vivo staining of nuclei, Hoechst 33342 (Sigma) was used at a concentration of $1 \mathrm{ng} /$ $\mathrm{mL}$. Internalized AuNPs were imaged as described above. Samples were observed through a $20 \times, 0.70$ N.A. objective or a $63 \times, 1.40$ N.A. oil immersion objective. The reproducibility of results was guaranteed by performing four independent biological replicates.

Acknowledgment. The authors gratefully acknowledge G. Vecchio for useful discussions, and B. Antonazzo, V. Fiorelli for the expert technical assistance.

Supporting Information Available: Additional DLS and TEM analyses of AuNPs suspended in DMEM and RPMI (10\% FBS); additional cellular tests to assess toxicity of AuNPs; table reporting proteins identified by means of $L C-M S / M S$ analysis from protein corona; quantitative ICP-AES analyses of cellular internalization of AuNPs in DMEM and RPMl; further characterization of protein corona formation in DMEM and RPMI (10\% FBS). This material is available free of charge via the Internet at http://pubs.acs.org.

\section{REFERENCES AND NOTES}

1. Nel, A.; Xia, T.; Mädler, L.; Li, N. Toxic Potential of Materials at the Nanolevel. Science 2006, 311, 622-627.

2. Auffan, M.; Rose, J.; Bottero, J. Y.; Lowry, G. V.; Jolivet, J. P.; Wiesner, M. R. Towards a Definition of Inorganic Nanoparticles from an Environmental, Health and Safety Perspective. Nat. Nanotechnol. 2009, 4, 634-641.

3. AshaRani, P. V.; Low Kah Mun, G.; Hande, M. P.; Valiyaveettil, S. Cytotoxicity and Genotoxicity of Silver Nanoparticles in Human Cells. ACS Nano 2009, 3, 279-290.

4. Napierska, D.; Thomassen, L. C. J.; Rabolli, V.; Lison, D.; Gonzalez, L.; Kirsch-Volders, M.; Martens, J. A.; Hoet, P. H. Size-Dependent Cytotoxicity of Monodisperse Silica Nanoparticles in Human Endothelial Cells. Small 2009, 5, 846-853.

5. Hauck, T. S.; Anderson, R. E.; Fischer, H. C.; Newbigging, S.; Chan, W. C. In Vivo Quantum-Dot Toxicity Assessment. Small 2010, 1, 138-144.

6. Pernodet, N.; Fang, X.; Sun, Y.; Bakhtina, A.; Ramakrishnan, A.; Sokolov, J.; Ulman, A.; Rafailovich, M. Adverse Effects of Citrate/Gold Nanoparticles on Human Dermal Fibroblasts. Small 2006, 2, 766-773.

7. Poland, C. A.; Duffin, R.; Kinloch, I.; Maynard, A.; Wallace, W. A. H.; Seaton, A.; Stone, V.; Brown, S.; MacNee, W.; Donaldson, K. Carbon Nanotubes Introduced into the Abdominal Cavity of Mice Show Asbestos-Like Pathogenicity in a Pilot Study. Nat. Nanotechnol. 2008, 3, 423-428.
8. Mortensen, L. J.; Oberdorster, G.; Pentland, A. P.; Delouise, L. A. In Vivo Skin Penetration of Quantum Dot Nanoparticles in the Murine Model: The Effect of UVR. Nano Lett. 2008, 8, 2779-2787.

9. Trouiller, B.; Reliene, R.; Westbrook, A.; Solaimani, P.; Schiestl, R. H. Titanium Dioxide Nanoparticles Induce DNA Damage and Genetic Instability in Vivo in Mice. Cancer Res. 2009, 69, 8784-8789.

10. Warheit, D. B.; Laurence, B. R.; Reed, K. L.; Roach, D. H.; Reynolds, G. A. M.; Webb, T. R. Comparative Pulmonary Toxicity Assessment of Single-Wall Carbon Nanotubes in Rats. Toxicol. Sci. 2004, 77, 117-125.

11. Maynard, A. D.; Aitken, R. J.; Butz, T.; Colvin, V.; Donaldson, K.; Oberdörster, G.; Philbert, M. A.; Ryan, J.; Seaton, A.; Stone, V.; et al. Safe Handling of Nanotechnology. Nature 2006, 444, 267-269.

12. Murdock, R. C.; Braydich-Stolle, L.; Schrand, A. M.; Schlager, J. J.; Hussain, S. M. Characterization of Nanomaterial Dispersion in Solution Prior to In Vitro Exposure Using Dynamic Light Scattering Technique. Toxicol. Sci. 2008, 101, 239-253.

13. Warheit, D. B. How Meaningful Are the Results of Nanotoxicity Studies in the Absence of Adequate Material Characterization. Toxicol. Sci. 2008, 101, 183-185.

14. Shvedova, A. A.; Kisin, E. R.; Mercer, R.; Murray, A. R.; Johnson, V. J.; Potapovich, A. I.; Tyurina, Y. Y.; Gorelik, O.; Arepalli, S.; Schwegler-Berry, D.; et al. Unusual Inflammatory and Fibrogenic Pulmonary Responses to Single-Walled Carbon Nanotubes in Mice. Am. J. Physiol. Luna Cell. Mol. Physiol. 2005, 289, L698-L708.

15. Park, M. V.; Annema, W.; Salvati, A.; Lesniak, A.; Elsaesser, A.; Barnes, C.; McKerr, G.; Howard, C. V.; Lynch, I.; Dawson, K. A.; et al.; In Vitro Developmental Toxicity Test Detects Inhibition of Stem Cell Differentiation by Silica Nanoparticles. Toxicol. Appl. Pharmacol. 2009, 240, 108-116.

16. Nel, A. E.; Mädler, L.; Velegol, D.; Xia, T.; Hoek, E. M.; Somasundaran, P.; Klaessig, F.; Castranova, V.; Thompson, $M$. Understanding Biophysicochemical Interactions at the Nano-Bio Interface. Nat. Mater. 2009, 8, 543-57.

17. Lynch, l.; Salvati, A.; Dawson, K. A. Protein-Nanoparticle Interactions: What Does the Cell See. Nat. Nanotechnol. 2009, 4, 546-547.

18. Cedervall, T.; Lynch, l.; Lindman, S.; Berggård, T.; Thulin, E.; Nilsson, H.; Dawson, K. A.; Linse, S. Understanding the Nanoparticle-Protein Corona Using Methods to Quantify Exchange Rates and Affinities of Proteins for Nanoparticles. Proc. Natl. Acad. Sci. U.S.A. 2007, 104, 20502055.

19. Lundqvist, M.; Stigler, J.; Elia, G.; Lynch, I.; Cedervall, T.; Dawson, K. A. Nanoparticle Size and Surface Properties Determine the Protein Corona with Possible Implications for Biological Impacts. Proc. Natl. Acad. Sci. U.S.A. 2008, 105, 14265-14270.

20. Dutta, D.; Sundaram, S. K.; Teeguarden, J. G.; Riley, B. J. Fifield, L. S.; Jacobs, J. M.; Addleman, S. R.; Kaysen, G. A.; Moudgil, B. M.; Weber, T. J. Adsorbed Proteins Influence the Biological Activity and Molecular Targeting of Nanomaterials. Toxicol. Sci. 2007, 100, 303-315.

21. Aggarwal, P.; Hall, J. B.; McLeland, C. B.; Dobrovolskaia, M. A.; McNeil, S. E. Nanoparticle Interaction with Plasma Proteins As It Relates to Particle Biodistribution, Biocompatibility and Therapeutic Efficacy. Adv. Drug Delivery Rev. 2009, 61, 428-437.

22. Oberdörster, G. Safety Assessment for Nanotechnology and Nanomedicine: Concepts of Nanotoxicology. J Intern Med. 2010, 267, 89-105.

23. Shaw, S. Y.; Westly, E. C.; Pittet, M. J.; Subramanian, A.; Schreiber, S. L.; Weissleder, R. Perturbational Profiling of Nanomaterial Biologic Activity. Proc. Natl. Acad. Sci. U.S.A. 2008, 105, 7387-7392.

24. Park, M. V.; Lankveld, D. P.; van Loveren, H.; de Jong, W. H. The Status of in Vitro Toxicity Studies in the Risk Assessment of Nanomaterials. Nanomedicine (London) 2009, 4, 669-685. 
25. Landsiedel, R.; Ma-Hock, L.; Kroll, A.; Hahn, D.; Schnekenburger, J.; Wiench, K.; Wohlleben, W. Testing Metal-Oxide Nanomaterials for Human Safety. Adv. Mater. 2010, 22, 2601-2627.

26. Oberdörster, G.; Maynard, A.; Donaldson, K.; Castranova, V.; Fitzpatrick, J.; Ausman, K.; Carter, J.; Karn, B.; Kreyling, W.; Lai, D.; et al. Principles for Characterizing the Potential Human Health Effects from Exposure to Nanomaterials: Elements of a Screening Strategy. Part. Fibre Toxicol. 2005, 2,8 .

27. Link, S.; El-Sayed, M. A. Spectral Properties and Relaxation Dynamics of Surface Plasmon Electronic Oscillations in Gold and Silver Nanodots and Nanorods. J. Phys. Chem. B 1999, 103, 8410.

28. Kelly, K. L.; Coronado, E.; Zhao, L. L.; Schatz, G. C. The Optical Properties of Metal Nanoparticles: The Influence of Size, Shape, and Dielectric Environment. J. Phys. Chem. B 2003, 107, 668-677.

29. Haes, A. J.; Van Duyne, R. P. A Nanoscale Optical Biosensor: Sensitivity and Selectivity of an Approach Based on the Localized Surface Plasmon Resonance Spectroscopy of Triangular Silver Nanoparticles. J. Am. Chem. Soc. 2002, 124, 10596-10604.

30. Jensen, T. R.; Malinsky, M. D.; Haynes, C. L.; Van Duyne, R. P. Nanosphere Lithography: Tunable Localized Surface Plasmon Resonance Spectra of Silver Nanoparticles. J. Phys. Chem. B 2000, 104, 10549-10556.

31. Fujiwara, K.; Watarai, H.; Itoh, H.; Nakahama, E.; Ogawa, N. Measurement of Antibody Binding to Protein Immobilized on Gold Nanoparticles by Localized Surface Plasmon Spectroscopy. Anal. Bioanal. Chem. 2006, 386, 639-644.

32. Lynch, I.; Cedervall, T.; Lundqvist, M.; Cabaleiro-Lago, C.; Linse, S.; Dawson, K. A. The Nanoparticle-Protein Complex as a Biological Entity; A Complex Fluids and Surface Science Challenge for the 21st Century. Adv. Colloid Interface Sci. 2007, 134-135, 167-174.

33. Walczyk, D.; Bombelli, F. B.; Monopoli, M. P.; Lynch, I.; Dawson, K. A. What the Cell "Sees" in Bionanoscience. J. Am. Chem. Soc. 2010, 132, 5761-5768.

34. Aslan, K.; Lakowicz, J. R.; Geddes, C. D. Plasmon Light Scattering in Biology and Medicine: New Sensing Approaches, Visions, and Perspectives. Curr. Opin. Chem. Biol. 2005, 9, 538-544.

35. Xiang, M.; Xu, X.; Li, D.; Liu, F.; Li, N.; Li, K. Selective Enhancement of Resonance Light-Scattering of Gold Nanoparticles by Glycogen. Talanta 2008, 76, 1207-1211.

36. Dobrovolskaia, M. A.; Patri, A. K.; Zheng, J.; Clogston, J. D.; Ayub, N.; Aggarwal, P.; Neun, B. W.; Hall, J. B.; McNeil, S. E. Interaction of Colloidal Gold Nanoparticles with Human Blood: Effects on Particle Size and Analysis of Plasma Protein Binding Profiles. Nanomedicine 2009, 5, 106-117.

37. Vroman, L.; Adams, A. Adsorption of Proteins out of Plasma and Solutions in Narrow Spaces. J. Colloid Interface Sci. 1986, 111, 391-402.

38. Cedervall, T.; Lynch, I.; Foy, M.; Berggard, T.; Donnelly, S. C.; Cagney, G.; Linse, S.; Dawson, K. A. Detailed Identification of Plasma Proteins Adsorbed on Copolymer Nanoparticles. Angew. Chem. Int. Ed. 2007, 46, 5754-5756.

39. Lynch, I.; Dawson, K. A. Protein-Nanoparticle Interactions. Nano Today. 2008, 3, 40-47.

40. Casals, E.; Pfaller, T.; Duschl, A.; Oostingh, G. J.; Puntes, V. Time Evolution of the Nanoparticle Protein Corona. ACS Nano 2010, 4, 3623-3632.

41. Alberts, A.; Johnson, A.; Lewis, J.; Raff, M.; Roberts, K.; Walter, P. Molecular Biology of the Cell; Garland Science: New York, 2002.

42. Yelin, D.; Oron, D.; Thiberge, S.; Moses, E.; Silberberg, Y. Multiphoton Plasmon-Resonance Microscopy. Opt. Exp. 2003, 11, 1385-1391.

43. Farrer, R. A.; Butterfield, F. L.; Chen, V. W.; Fourkas, J. T. Highly Efficient Multiphoton-Absorption-Induced Luminescence from Gold Nanoparticles. Nano Lett. 2005, 5, 1139-1142.
44. Turkevich, J.; Stevenson, P. C.; Hillier, J. A Study of the Nucleation and Growth Processes in the Synthesis of Colloidal Gold. Discuss. Faraday. Soc. 1951, 11, 55-75.

45. Frens, G. Controlled Nucleation for the Regulation of the Particle Size in Monodisperse Gold Suspensions. Nat., Phys. Sci. 1973, 241, 20-22.

46. Zou, X.; Ying, E.; Dong, S. Seed-Mediated Synthesis of Branched Gold Nanoparticles with the Assistance of Citrate and Their Surface-Enhanced Raman Scattering Properties. Nanotechnology 2006, 17, 4758-4764.

47. Stremsdoerfer, G.; Perrot, H.; Martin, J. R.; Clechet, P. J. Autocatalytic Deposition of Gold and Palladium onto nGaAs in Acidic Media. Electrochem. Soc. 1988, 135 2881-2885.

48. Lee, J. S.; Stoeva, S. I.; Mirkin, C. A. DNA-Induced SizeSelective Separation of Mixtures of Gold Nanoparticles. J. Am. Chem. Soc. 2006, 128, 8899-8903.

49. Zhu, Y.; Wu, Z.; Tang, Z.; Lu, Z. HeLa Cell Adhesion on Various Collagen-Grafted Surfaces. J. Proteome Res. 2002, 1, 559-562.

50. Girard-Lauriault, P. L.; Truica-Marasescu, F.; Petit, A.; Wang, H. T.; Desjardins, P.; Antoniou, J.; Mwale, F.; Wertheimer, M. R. Adhesion of Human U937 Monocytes to NitrogenRich Organic Thin Films: Novel Insights into the Mechanism of Cellular Adhesion. Macromol. Biosci. 2009, 9, 911-921. 